\title{
PATIENTS NEED TO RECEIVE THE SAME KIND OF INFORMATION ABOUT THE SAME ISSUE FROM EACH PROFESSIONAL
}

\author{
Ilze Ansule \\ Riga Stradiņš University, Latvia \\ Anda Kīììte-Urtāne \\ Riga Stradiņš University, Latvia \\ Inga Millere \\ Riga Stradiņš University, Latvia
}

\begin{abstract}
The questionnaire has been developed from a validated instrument "Women's Experience of Maternity Care" (author - National Health Service, (Great Britain, 2019) and adapted to the situation in Latvia. The permission to use it has been obtained from authors. The questionnaire is meant for women regardless of their health status during the perinatal period or who have no co-morbidities, diagnosed in perinatal period of care. The questionnaire is designed to find out patients' experiences of receiving healthcare and its compliance with the guidelines, identifying potential problems and creating opportunities to correct them. There were 50 patients in Maternity Hospital postpartum unit interviewed. 12 of them were women living with HIV. Results. One of five main comment themes was - patients felt the need to receive the same kind of information about the same issue from all health care professional regardless of staff changes on call. The women point out that they have no problems with content in communication process during intranatal period, at labor unit. The problem with different kind of information about the same matter is emerging in postpartum period, at maternity unit. This issue is bothering both groups of patients in postnatal period, those women who live with HIV and those who have no co-morbidities, diagnosed in perinatal period. This shows that there is different kind of knowledge and professional skills among health care professionals, even if they work in the same field, the same hospital and the same unit. There should be done more research to identify the source of this problem. Is it the different experience, knowledge, informational field where professionals seek for information or totally different reason for this phenomena.
\end{abstract}

Keywords: communication, medical personnel, perinatal health care, women`s experience.

\section{Introduction}

World Health Organization (WHO) has been defined effective communication as one of the major key points in Standards for providing qualitative perinatal health care: "The aim of this standard is effective communication, which is an essential component of the experience of care 
Ansule et al., 2021. Patients Need to Receive the Same Kind of Information about the Same Issue from Each Professional

received by the patient and her family," (WHO, 2016). In the same time in the duties of midwife is defined ability to give evidence based support and not only in Latvian language, but also in two foreign languages (VM, 2014). Keeping this in mind, there should be no excuses that information and care has not been given adequately on basis that women does not speak Latvian. The decision to make research for measuring the quality of perinatal health care thru patients reported experience is not unique, it has been done in other countries and showed significant results in improving quality of care: "The concept of experience of care as a critical aspect of ensuring high-quality childbirth care and improved woman-centered outcomes, and not just complementary to provision of routine clinical practices,” (Mukherjee et al., 2018; WHO, 2018).

The term "perinatal health care quality”, as Graham defines it: "Quality” recognizing the six elements of effectiveness, safety, timeliness, efficiency, equity and responsiveness to the preferences and needs and values of mothers and their families - as individuals and populations," shows how important are women `s and their family needs ( Graham, 2009). There is no more only definitions and list of what manipulations should be done, the major emphasis is on women`s needs or expectancies: "On the basis of several definitions in the literature, the WHO definition of quality of care is the extent to which health care services provided to individuals and patient populations improve desired health outcomes. In order to achieve this, health care must be safe, effective, timely, efficient, equitable and people-centred," (WHO, 2016). Researches highlights problems in health care process communication if patients are different or healthy in traditional opinion: "Disabled women perceived greater problems regarding their maternity care, communication and involvement in decision making than non-disabled women," (Malouf et al., 2015). As WHO report shows there is still stigma in perinatal care period for women living with HIV (WHO, 2016). These women are still seen as someone different and are not receiving the same attitude and information as other women: "There is a complex interplay of experiences of mistreatment and lack of support that impact women's childbirth experiences and outcomes," (Tuncalp et al., 2015; Lyndon et al., 2015). In 2018 WHO made clear that: "The guideline recognizes a "positive childbirth experience" as a significant end point for all women undergoing labour. It defines a positive childbirth experience as one that fulfils or exceeds a woman's prior personal and sociocultural beliefs and expectations, including giving birth to a healthy baby in a clinically and psychologically safe environment with continuity of practical and emotional support from a birth companion(s) and kind, technically competent clinical staff," (WHO, 2018). It changed all the concept of perinatal health care, from this moment it was made clear that there should be positive childbirth experience for every women regardless their health or social status. For health care professionals it was clear signal that performing correct manipulations does not mean patient 
centred care: "Prioritize person-centred health and well-being, not only the prevention of death and morbidity, in accordance with a human rights-based approach," (Lyndon et al., 2015; Madula, Kalembo, Hong Yu, Kaminga, 2018; WHO, 2016). Nowadays health practitioners should also be aware of in what way and how they speak to patient. As patients seek informotaion not only from professionals, but in media all around the World (Kamiński, 2020).

\begin{abstract}
Aim
Gather the information about women's, who are living with and without HIV, experience about perinatal health care in the last childbirth.
\end{abstract}

\title{
Method
}

This questionnaire was made in frame of a pilot study in the $\mathrm{PhD}$ thesis research "Quality of perinatal health care and it`s influencing factors for patients who are living with HIV in Latvia" carried out in of the Maternity Hospitals, in Latvia, using the structured questionnaire. The questionnaire has 7 sections about each perinatal health care period and breastfeeding, new born care, home care, household and comment section at the end for anything what women might want to tell or interviewer ask more about perinatal health care process in all together. In questionnaire last section is possible in free manner to ask about women`s perinatal health care experience. This has been done for two times with each person; first time at postpartum unit (using direct interview) and $8-10$ weeks after childbirth (using telephone interview) to gather information about postpartum period. The questionnaire had been adapted according to the guidelines (Beaton et al., 2000). As the questionnaire is designed to find out patients' experiences of receiving healthcare and its compliance with the guidelines it is easy to find out the problem points. Prior to the interview, each respondent was explained the purpose of the study and the principle of volunteering. The information in pilot study was gathered from 50 women. Fiftysix women were addressed and six refused to participate in the pilot study. Women were addressed only after giving birth with a positive result, so that the principle of "making no harm" was observed. After filling the questions about medical history, women were asked to comment in free manner their experience and south's about received perinatal health care.

\section{Results}

Problems with received different kind of information from medical personnel about the same issue appeared in pilot study equally in both groups; 
Ansule et al., 2021. Patients Need to Receive the Same Kind of Information about the Same Issue from Each Professional

those women who live with HIV and those who have no co-morbidities, diagnosed in perinatal period of care. The main six problem points in communication:

- concerns about different kind of information about the same issue during antenatal period;

- $\quad$ professional attitude towards patient; lack of given information and negative attitude was the only reason why women changed their health care provider during antenatal period;

- $\quad$ in early days of postpartum period women describe their anxiety about received different kind of information about the same issue almost every day;

- $\quad$ possible solution could be written guidelines, as they could be seen for both: patients and medical stuff;

- $\quad$ need for empathy;

- $\quad$ seeking for "ultimate truth".

\section{Antenatal care}

The women described their concerns about different kind of information about the same issue during antenatal period as very alarming. For example, gynecologist is describing their 14th week ultrasound as normal/usual. But professional who performed it was concerned about some development issues, as women understood it from his facial expressions, but did not explained to her what was the matter, when she asked about it.

"I asked what was the problem, but he just said to come for the second screening and then he will see.” (RD8)

There also could be discussion was it only misunderstood communication issues or professional attitude to patient. This women also added that she went to a different specialist for the next screening and was satisfied how everything was explained, without even asking.

The lack of given information and negative attitude was the only reason why women changed their health care provider during antenatal period.

"He did not explained anything. Just said come after three weeks and that was all. This other doctor explained everything. I even had no questions!” (RD9)

There were also reported negative attitude and misleading information about antenatal health care for women living with HIV.

"You can`t be a mother. What do you expect?" (RD 50)

After changing the health care giver, in different town, there were no problems in the way information has been given or content of it.

Giving birth and first days after

In early days of postpartum period women describe their anxiety about received different kind of information about the same issue almost every day. 
"The suggestions of the nurses are different. One day they say one, another day they say another." (RD7)

As it is the very difficult time for each women by itself this information clutter does not help. As women point out that they are really trying to do their best, as they have been told each morning, - in breast feeding, physical activities and nutrition aspects, but then comes the next morning with other personnel and information is completely different. Some women even pointed out that possible solution could be written guidelines, as they could be seen for both; patients and medical stuff (Lyndon et al., 2015).

There were reported also not-positive experience, not only about information, content, but attitude also.

"One day the pediatrician says one ... But yesterday said otherwise. Angry, but I'm already worried.” (RD1)

The women described their need for empathy during this challenging period of time, they not only have not received it, but even experienced angry attitude. The women were seeking for understanding and support. Even without asking, women suggested that possible reason for personnel angry attitude could be overwork.

There were also absolutely positive experience about received care and information.

"It`s absolutely fabulous! Everybody is so nice." (RD45)

\section{Postpartum period}

As the main problem in information content women describe misunderstandings about their diet during breast feeding period.

"The GP said that I can`t eat apples and berries, but my midwife said that I can eat everything”. (RD 11)

Comments show women`s concerns about issue trying to be "a good mother”, but not succeeding. As they follow one professionals advice, but then comes another one, who says that they are making harm to their child. Women tell that after those misunderstandings they spend a lot of time in social media seeking for "ultimate truth", as professionals have no consensus.

\section{Discussion}

All women regardless of their health status during the perinatal period, but especially those, who live with HIV, as they have more health issues and concerns, are seeking for supportive and well trained personnel: "Supportive and well-trained providers are vital to helping HIV-infected expectant mothers seek and adhere to prenatal care and HIV treatment,” (Aigbe, 2014). 
Ansule et al., 2021. Patients Need to Receive the Same Kind of Information about the Same Issue from Each Professional

During antenatal period there is no big differences between what are the women`s values in care: "Evidence showed that women from high-, medium- and low-resource settings valued having a positive pregnancy experience, the components of which included the provision of effective clinical practices (interventions and tests, including nutritional supplements), relevant and timely information (including dietary and nutritional advice) and psychosocial and emotional support, by knowledgeable, supportive and respectful health-care practitioners, to optimize maternal and new-born health (high confidence in the evidence)" (Lyndon et al., WHO, 2016). The women described their essential need to know what are the possibilities for birth and possible scenarios: "Advice and support to the woman and her family in developing a birth and emergency preparedness plan. Provide appropriate health education to all pregnant women and their partners and families, including healthy lifestyles, healthy diet, smoking cessation where required, preparation for parenthood, relaxation therapy and/or other activities as required, such as exercises to prepare the woman for the process of birth," (WHO, 2007).

Why the correct information matters, especially during postnatal period? As the WHO data shows, it is a most critical period during the perinatal period, for both as for women, as new-borns: "The postnatal period is a critical phase in the lives of mothers and new-born babies. Most maternal and infant deaths occur during this time," and there should be unity in information from all the medical personnel (Yu, Lee, Sherwood \& Kim 2018; WHO, 2013).

Women who described their anxiety added, that sometimes they don`t know, is the current state of mind normal or they should be concerned. It is still different kind of guidelines for screening for PPD "There is little evidence to recommend first screening method over another; therefore, clinicians may choose the method most consistent with their personal preference, the patient population being served, and the practice setting”, and other issue is medical personnel's communication with each other, - how they exchange with each other received information from patients (ACOG, 2012; Matzke, Houston, Fischer, \& Bradshaw 2014).

Still there are other problems with personnel communication, as women reported, and they show similar results to WHO report on 2016: "Some health care providers at primary level show- low awareness about the scale of HIV problems and some reluctance to deal with HIV positive patients, stigma towards HIV patients, low motivation to carry out quality post-test HIV counselling” (WHO, 2016). As the Ministry of Health documents shows there is still lack of eagerness to be involved in perinatal health care for women living with HIV from medical personnel (VM, 2017). 


\section{Conclusions}

As this pilot study shows there are different kind of knowledge and professional skills among health care professionals, even if they work in the same field, the same hospital and the same unit.

The one of possible explanations could be that they are from different generations and from different professional education systems. From other side we all live in "life long" learning era. There is no such thing anymore as: "I learned it at university." Guidelines are changing, but they are available at the same time for every body via internet. There is still one issue and that is language barrier. There are medical professionals who still won `t be able to catch up newest guidelines as they are not able to read them. Only after they have been translated. But it could not be an excuse for every time as there are a lot of guidelines in official sites in Latvian (VM, 2020; GINASOC, 2020; SPKC, 2017; E-veselība, 2019).

There are activists among medical professionals who share their knowledge of newest guidelines and research papers: "Effective leaders of change can arise from frontline individuals who may or may not already be identified as leaders" (Nathan, 2017; Kaminski, 2020).

There should be done more research work to look for possible reasons of differences in information content and its given form to patients in perinatal period.

\section{References}

ACOG. (2012). Maternity care Performance Measurement. Retrieved from https://www.ahrq.gov/sites/default/files/wysiwyg/CHIPRA-BMI-Maternity-CareMeasures.pdf

Afulani, P. A., Buback, L., Kelly, A. M., Kirumbi, L., Cohen, C. R., \& Lyndon, A. (2020). Providers' perceptions of communication and women's autonomy during childbirth: a mixed methods study in Kenya. Reproductive Health, 17, 1-17. https://doi.org/ 10.1186/s12978-020-0909-0. Retrieved from https://search-proquest-com.db.rsu.lv/ docview/2414808395?pq-origsite=primo

Aigbe, A. O. (2014). Poviders' Perspectives on Bariers to care, System Constraints and piloting the HIV-modified centering Pregnancy Model among HIV-positive pregnant women. Research Gate. Retrieved from https://digitalcommons.library.tmc.edu/dissertations/ AAI3665069/

Beaton, D. E., Bombardier, C., Guillemin, F., Bosi Ferraz, M. (2000). Guidelines for the Process of Cross-Cultural Adaptation of Self-Report Measures, PMID: 11124735 DOI: 10.1097/00007632-200012150-00014 Retrieved from https://pubmed.ncbi.nlm.nih.gov/ $11124735 /$

DeBaets, A. M. (2017). From birth plan to birth partnership: enhancing communication in childbirth. American journal of obstetrics and gynecology, 216(1), 31-e1. Retrieved from 
Ansule et al., 2021. Patients Need to Receive the Same Kind of Information about the Same Issue from Each Professional

https://www-sciencedirectcom.db.rsu.lv/science/article/pii/S0002937816308080?via\%3Dihub

E-veseliba. (2019). “Vai Tu zini visu par HIV?” Retrieved from https://www.eveseliba.gov.lv/ sakums/informativie-raksti/reproduktiva-veseliba/seksu\%C4\%81litransmis\%C4\%ABv\%C4\%81s-slim\%C4\%ABbas/vai-tu-zini-visu-par-hiv

GINASOC. (2020). Vadlīnijas un rekomendācijas dzemdību speciālistiem. Retrieved from https://www.ginasoc.lv/kliniskas-rekomendacijas-2

Graham, W. J. (2009). Criterion-based clinical audit in obstetrics: bridging the quality gap? Best practice \& research Clinical obstetrics \& gynaecology, 23(3), 375-388. Retrieved from https://europepmc.org/article/med/19299203

Kamiński, M., Łoniewski, I., \& Łoniewska, B. (2020). 'Dr. Google, is caesarean section good for me?'- the global Internet searches associated with mode of birth methods: Retrospective analysis of Google trends data. Midwifery, 89, 102787.

Lyndon, A., Johnson, M. C., Bingham, D., Napolitano, P. G., Joseph, G., Maxfield, D. G., \& O'Keeffe, D. F. (2015). Transforming communication and safety culture in intrapartum care: A multi-organization blueprint. Journal of Obstetric, Gynecologic \& Neonatal Nursing, 44(3), 341-349. Retrieved from https://www-sciencedirect-com.db.rsu.lv/ science/article/abs/pii/S0884217515318128

Madula, P., Kalembo, F. W., Yu, H., \& Kaminga, A. C. (2018). Healthcare provider-patient communication: a qualitative study of women's perceptions during childbirth. Reproductive health, 15(1), 1-10. https://doi.org/10.1186/s12978-018-0580-x, Retrieved from https://search-proquest-com.db.rsu.lv/docview/2089764180?pq-origsite=primo

Malouf, R., Henderson, J., \& Redshaw, M. (2017). Access and quality of maternity care for disabled women during pregnancy, birth and the postnatal period in England: data from a national survey. BMJ open, 7(7), e016757. Retrieved from https://bmjopen.bmj.com/ content/7/7/e016757

Matzke, B., Houston, S., Fischer, U., \& Bradshaw, M. J. (2014). Using a team-centered approach to evaluate effectiveness of nurse-physician communications. Journal of Obstetric, Gynecologic \& Neonatal Nursing, 43(6), 684-694. Retrieved from https://www-sciencedirect-com.db.rsu.lv/science/article/abs/pii/S0884217515316099

Mukherjee, S., Fennie, K., Coxe, S., Madhivanan, P., \& Trepka, M. J. (2018). Racial and ethnic differences in the relationship between antenatal stressful life events and postpartum depression among women in the United States: does provider communication on perinatal depression minimize the risk? Ethnicity \& health, 23(5), 542-565. https://doi.org/10. 1080/13557858.2017.1280137. Retrieved from http://web.a.ebscohost.com.db.rsu.lv/ ehost/pdfviewer/pdfviewer?vid=1\&sid=925b6e46-ffe1-467a-a698-103596cb5c3a\%40 sdc-v-sessmgr03

Nathan, A. T. \& Kaplan, H. C. (2017). Tools and methods for quality improvement and patient safety in perinatal care. Elsevier, PMID: 28552386 DOI: 10.1053/j.semperi.2017.03.002 Retrieved from https://pubmed.ncbi.nlm.nih.gov/28552386/

NHS. (2019). Women's Experience of Maternity Care. Retrieved from https://www.cqc.org.uk/ sites/default/files/20200128_mat19_technicaldocument.pdf

SPKC. (2017). Piemērots uzturs, plānojot grūtniecību un grütniecības laikā, - veselīga dzīves sākuma pamats. Retrieved from https://www.spkc.gov.lv/lv/ieteikumi-veselibasaprupes-specialistiem-piemerots-uzturs-planojot-grutniecibu-un-

grutniecibas/ieteik_prof_grutn1.pdf 
Tunçalp, Ö., Were, W. M., MacLennan, C., Oladapo, O. T., Gülmezoglu, A. M., Bahl, R., ... \& Bustreo, F. (2015). Quality of care for pregnant women and newborns-the WHO vision. BJOG: an international journal of obstetrics \& gynaecology, 122(8), 1045-1049.

VM. (2020). HIV infekcija. Retrieved from https://www.spkc.gov.lv/lv/hiv-infekcija

VM. (2014). Vecmātes profesijas standarts, 13., 27. pants. Retrieved from http://www.vecmasuasociacija.lv/wp-content/uploads/Standrt.apstipr..pdf

VM. (2017). "HIV infekcijas, seksuālās transmisijas infekciju, B un C hepatīta izplatības ierobežošanas rīcības plāns 2018. - 2020.gadam”. Retrieved from https://likumi.lv/ ta/id/294753-par-hiv-infekcijas-seksualas-transmisijas-infekciju-b-un-c-hepatitaizplatibas-ierobezosanas-ricibas-planu-2018-2020-gada

WHO. 2016). Mission to assess readiness for validation of the elimination of mother to child transmission of HIV. Retrieved from https://www.euro.who.int/en/countries/latvia/ publications/mission-to-assess-readiness-for-validation-of-the-elimination-of-motherto-child-transmission-of-hiv-latvia,-23-27-may-2016

WHO. (2016). Standards for improving quality of maternal and new-born care in health facilities. Retrieved from https://www.who.int/maternal_child_adolescent/documents/ improving-maternal-newborn-care-quality/en/

WHO. (2007). Standards for Maternal and Neonatal Care. Retrieved from https://www.who. int/reproductivehealth/publications/maternal_perinatal_health/a91272/en/

WHO. (2016). WHO recommendations on antenatal care for a positive pregnancy experience. Retrieved from https://www.who.int/publications/i/item/9789241549912

WHO. (2013). WHO recommendations on postnatal care of the mother and new-born. Retrieved from https://www.who.int/maternal_child_adolescent/documents/postnatalcare-recommendations/en/

WHO. (2018). WHO recommendations: intrapartum care for a positive childbirth experience. Retrieved from https://www.who.int/reproductivehealth/publications/intrapartum-careguidelines/en/

Yu, M., Lee, H. Y., Sherwood, G., \& Kim, E. (2018). Nurses' handoff and patient safety culture in perinatal care units: Nurses' handoff evaluation and perception of patient safety culture at delivery room and neonatal unit in South Korea. Journal of clinical nursing, 27(7-8), e1442-e1450. 